Open Access

Original Article

\title{
On pump harvesting of Left Internal Mammary Artery (LIMA) in unstable patients undergoing coronary artery bypass grafting $(C A B G)$ is a safe operative strategy: A pilot study
}

\author{
Muhammad Sher-i-Murtaza', Mirza Ahmad Raza Baig²
}

\begin{abstract}
Objective: To evaluate the clinical safety of left internal mammary artery (LIMA) harvesting in hemodynamically unstable patients after establishing cardiopulmonary bypass (CPB) in isolated coronary artery bypass graft (CABG) surgery.

Methods: The prospective observational study was conducted at Chaudhry Pervaiz Elahi Institute of Cardiology, Multan, Pakistan, from December 2016 to August 2018. All patients undergoing isolated CABG surgery in which LIMA conduit was harvested after establishing cardiopulmonary bypass because of hemodynamic instability at induction of anaesthesia or during surgery were included in the study. Preoperative, operative and postoperative characteristics of the patients were recorded. Data was analyzed using SPSS 19.

Results: In Forty nine patients including 39 male and 10 female, early CPB had to be established because of hemodynamic instability and afterwards LIMA was harvested. Out of 49, 30 patients presented with CCS class III angina. 37 (75.5\%) patients were scheduled on elective coronary surgery waiting list. There were $39(79.59 \%)$ patients who weaned off bypass on mild inotropic support and $4(8.16 \%)$ patients needed IABP support. All patients had multi-vessel coronary artery disease. Mean number of grafts were $3.428 \pm 0.577$, CPB time was $110.59 \pm 25.594$ and hospital stay was $5.367 \pm 1.424$.

Conclusions: The study showed that LIMA can be safely harvested in unstable patients after establishing extracorporeal circulation and by using this operative strategy in patients who need urgent or emergent surgical coronary revascularization LIMA can be safely used as a conduit.
\end{abstract}

KEYWORDS: Coronary artery bypass grafting, Left internal mammary artery, Cardiopulmonary bypass.

How to cite this:

doi: https://doi.org/10.12669/pjms.35.3.988

Sher-i-Murtaza M, Baig MAR. On pump harvesting of Left Internal Mammary Artery (LIMA) in unstable patients undergoing coronary artery bypass grafting (CABG) is a safe operative strategy: A pilot study. Pak J Med Sci. 2019;35(3):605-608. doi: https://doi.org/10.12669/pjms.35.3.988

This is an Open Access article distributed under the terms of the Creative Commons Attribution License (http://creativecommons.org/licenses/by/3.0), which permits unrestricted use, distribution, and reproduction in any medium, provided the original work is properly cited.

\section{INTRODUCTION}

Correspondence:

Dr. Muhammad Sher-i-Murtaza

Postal Address: H.NO 177/1, Main Street NO \#3,

Ali Park View near Bajwa Chowk,

Qasim Bela, Multan.

Email: ahmadraza.perfusion@gmail.com sherm.cpeic@gmail.com

* Received for Publication:

* Lou and EC saved:

* Revision Received:

* Revision Accepted:
October 18, 2018

October 31, 2018

March 13, 2019

March 20, 2019
Surgical revascularization is an effective treatment modality to treat coronary artery disease. In Coronary Artery Bypass Graft (CABG) surgery, the use of left internal mammary artery (LIMA) to bypass significant left anterior descending (LAD) artery stenosis has been proven by studies as a gold standard clinical practice. These studies have shown that LIMA graft has better long-term patency. ${ }^{1-3}$ LAD supplies major territory of left ventricle in majority of cases, ${ }^{4}$ hence a graft to LAD 
territory if remains patent for decades; benefits of CABG surgery can be prolonged resulting in better and event free long term survival. In isolated CABG, one of reason of not using LIMA is urgent or emergent surgery and hemodynamic unstable condition of the patient. ${ }^{5,6}$

We harvested LIMA in this sub group of patients after establishing cardiopulmonary bypass and used this gold standard conduit to bypass LAD stenosis. Early outcome of these patients were studied to analyze safety of this strategy.

\section{METHODS}

This prospective observational study was conducted in department of cardiac surgery Chaudhry Pervaiz Elahi Institute of cardiology (CPEIC), Multan, Pakistan. All Patients undergoing isolated CABG surgery who were unstable or became unstable at induction of anesthesia or during or after sternotomy were included in the study.

The study was conducted from December 2016 to August 2018. Patient was considered hemodynamic unstable if he or she developed low blood pressure along with any of the following features.

- Significant STT changes in ECG monitor during induction of anaesthesia or during surgery,

- Rise in central venous pressure (CVP),

- Repeated or continuous need of inotropic support to maintain blood pressure,
- Bradycardia

- Tachycardia

- Tense PA with visible poor left ventricular (LV) contractility

- Aborted cardiac arrest

This study had approval from the ethical committee of the institution. In all our cases, median sternotomy was the approach used to access the heart for coronary bypass surgery. Heparin was administered in a dose of $400 \mathrm{IU} / \mathrm{Kg}$. The cardiopulmonary bypass (CPB) was established with aortic and two stage right atrial cannula. Either on pump beating or cold blood cardioplegic arrest technique was used for myocardial protection in these patients. In all patients, LIMA was harvested after establishing cardiopulmonary bypass.

The inotropic support used during weaning from cardiopulmonary bypass (CPB) and in Intensive care unit (ICU) was noted It was mild when dobutamine was administrated at a rate $<5 \mathrm{ug} / \mathrm{kg} /$ $\mathrm{min}$, moderate when used at $5-10 \mathrm{ug} / \mathrm{kg} / \mathrm{min}$ and high dose when dobutamine was administrated at $>10 \mathrm{ug} / \mathrm{kg} / \mathrm{min}$. Adrenaline or nor-adrenaline dose $<0.06 \mathrm{ug} / \mathrm{kg} / \mathrm{min}$ was considered as mild support, 0.06 to $1.0 \mathrm{ug} / \mathrm{kg} / \mathrm{min}$ as moderate and $>1 \mathrm{ug} / \mathrm{kg} / \mathrm{min}$ was considered as high inotropic support.

Maximum postoperative CK-MB levels were noted within 48 hours after surgery. A rise in CKMB levels more than five times the reference value

Table-I: Numeric variable of patients.

\begin{tabular}{lcccc}
\hline & Minimum & Maximum & Mean & Std. Deviation \\
\hline Age & 35.00 & 83.00 & 55.91 & 9.93 \\
grafts & 3.00 & 5.00 & 3.42 & 0.57 \\
Clamp time* $_{\text {CPB time* }}$ & 34.00 & 107.00 & 62.73 & 17.86 \\
Ventilation time** $_{\text {CKMB }}$ & 61.00 & 154.00 & 110.59 & 25.59 \\
ICU stay** & 3.00 & 28.00 & 6.61 & 4.57 \\
Hospital stay & 18.00 & 169.00 & 57.65 & 26.75 \\
Parsonet & 24.00 & 48.00 & 29.77 & 8.75 \\
Add.Euro & 3.00 & 11.00 & 5.36 & 1.42 \\
Log.Euro & 0.00 & 24.00 & 4.79 & 4.52 \\
EF\% & 0.00 & 8.00 & 1.38 & 1.66 \\
\hline
\end{tabular}

*minutes, ${ }^{* *}$ hours, ${ }^{* * *}$ days

$\mathrm{CPB}=$ cardiopulmonary bypass, $\mathrm{ICU}=$ intensive care unit, $\mathrm{CKMB}=$ Creatinine kinase myocardial band. 
was considered as perioperative MI. In hospital mortality was recorded. The preoperative, operative and postoperative characteristics were summarized using mean \pm standard deviation for the numeric variables and frequency for categorical variables (Table-I \& II).

\section{RESULTS}

In forty-nine (49) patients including 39 males and 10 females (3.9:1), LIMA was harvested after establishing cardiopulmonary bypass. Majority of patients who became unstable during surgery was presented with angina CCS class III $(61.2 \%)$ and $75.5 \%$ was on elective priority list. Out of $49,39(76.9 \%)$ patients weaned off from

Table-II: Categorical variables of patients.

\begin{tabular}{|c|c|c|}
\hline Name of variable & $\begin{array}{c}\text { Number of } \\
\text { Patients }\end{array}$ & Percentage \\
\hline Total number of patients & 49 & $100 \%$ \\
\hline \multicolumn{3}{|l|}{ Gender } \\
\hline Male & 39 & 79.6 \\
\hline Female & 10 & 20.4 \\
\hline \multicolumn{3}{|l|}{ Angina Class } \\
\hline Class II & 5 & 10.2 \\
\hline Class III & 30 & 61.2 \\
\hline Class IV & 14 & 28.6 \\
\hline \multicolumn{3}{|c|}{ LV Systolic Functional Grade } \\
\hline Grade I & 24 & 49.0 \\
\hline Grade II & 13 & 26.5 \\
\hline Grade III & 12 & 24.5 \\
\hline \multicolumn{3}{|l|}{ Priority of surgery } \\
\hline Elective & 37 & 75.5 \\
\hline Urgent & 10 & 20.4 \\
\hline Emergent & 2 & 4.1 \\
\hline \multicolumn{3}{|l|}{ IABP } \\
\hline Not used & 45 & 91.8 \\
\hline Per-op & 3 & 6.1 \\
\hline Pre-op & 1 & 2.0 \\
\hline \multicolumn{3}{|l|}{ Inotropes } \\
\hline Mild & 39 & 79.6 \\
\hline Moderate & 8 & 16.3 \\
\hline High & 2 & 4.1 \\
\hline
\end{tabular}

bypass on mild inotropic support. In 45 (91.8\%) patients there was no need of IABP (intra aortic balloon pump). Only four patients needed IABP peroperatively. Forty five patients underwent conventional CABG and four patients had on pump beating heart CABG surgery. All patients had multi-vessels coronary artery disease and mean graft applied was $3.42 \pm 0.57$. Mean clamp time was $62.73 \pm 17.86$ minutes and mean bypass time was $110.59 \pm 25.594$. Mean hospital stay of studied patients was $5.36 \pm 1.424$ days. One patient expired on $6^{\text {th }}$ postoperative day due to respiratory failure. Operative mortality was $2.04 \%$. One patient developed perioperative Myocardial infarction.

\section{DISCUSSION}

Studies have revealed that in patients requiring urgent or emergency revascularization the rate for LIMA usage was $61.5 \%$ compared with $92.5 \%$ in the non-emergent group. ${ }^{7}$ This is a fairly common reason for non-usage of LIMA. The lower rate of LIMA usage in this group of patients is likely to be due to hemodynamic instability or a greater risk of bleeding (as these patients are often on antithrombotic and antiplatelet therapy), ${ }^{5,6}$

In routine surgical practice, LIMA is harvested before establishing extracorporeal circulation or cardiopulmonary bypass. Patients with severe multi-vessel CAD and tight Left main stem stenosis can become unstable during induction of anesthesia or during surgery ${ }^{8}$ Routine clinical practice in these patients is to establish urgent cardiopulmonary bypass, and only vein conduit is used to bypass all significant coronary stenotic lesions which is easy and rapid to harvest in such scenario. Hence these patients are deprived of LIMA graft and its long term benefits. Literature review has revealed that in such emergent situation, experienced surgeons can harvest the LIMA in a relatively short time ${ }^{6}$ but this not always safe to harvest LIMA in presence of hemodynamic instability and under shear stress. It may jeopardize safety of patient because of inadequate organ perfusion due to hemodynamic instability and can result in damage to LIMA because of hustle.Many studies have shown that early establishment of extracorporeal circulation is affective and useful even in patients with emergency cardiac arrest. ${ }^{9,10}$

After establishing $\mathrm{CPB}$ there is significant reduction of myocardial $\mathrm{O}_{2}$ consumption of empty beating heart. As reported by Allen BS and 
colleagues that the $\mathrm{O}_{2}$ requirement of beating empty heart is reduced more than $50 \%$ as compared to the beating filled heart. ${ }^{11}$ Taking the concept from these studies, when we established cardiopulmonary bypass in unstable patients, the body perfusion is supported and maintained by a pump and not by heart.

We believe that LIMA can be safely harvested after establishing cardiopulmonary bypass in hemodynamically unstable patients without compromising systemic organ perfusion and safety of the patients. After establishing cardiopulmonary bypass, heart becomes empty; there is a decrease in LVEDV, wall tension, work load and oxygen demand. Force of contractility is reduced by avoiding the use of catecholamine to maintain systemic perfusion in ischemic heart while maintaining adequate coronary perfusion on pump. $^{12}$

Limitation of this study: It is small sample size study. So there is a need to conduct larger multi-center studies to determine the adequacy of on-pump LIMA harvesting in hemodynamically unstable patients.

\section{CONCLUSION}

Based on the results of this study we believe that in urgent or emergent condition left internal mammary artery can be safely harvested and hemodynamic instability is no longer a relative contraindication for LIMA harvesting.

\section{Grant Support E Financial Disclosures: None.}

\section{REFERENCES}

1. Lytle BW, Loop FD, Cosgrove DM, Ratliff NB, Easley K, Taylor PC. Long-term (5 to 12 years) serial studies of internal mammary artery and saphenous vein coronary bypass grafts. J Thorac Cardiovasc Surg. 1985;89(2):248-258.

2. Aldea GS, Bakaeen FG, Pal J, Fremes S, Head SJ, Sabik J, et al. The Society of Thoracic Surgeons clinical practice guidelines on arterial conduits for coronary artery bypass grafting. Ann Thorac Surg. 2016;101(2):801-809.doi: 10.1016/j.athoracsur.2015.09.100

3. Sabik III JF, Lytle BW, Blackstone EH, Houghtaling $\mathrm{PL}$, Cosgrove DM. Comparison of saphenous vein and internal thoracic artery graft patency by coronary system. Ann Thorac Surg. 2005;79(2):544-551. doi: 10.1016/j. athoracsur.2004.07.047
4. Rehman I, Rehman A. Anatomy, Thorax, Heart, Arteries, Left Anterior Descending (LAD). In StatPearls [Internet]. 2018.

5. Karthik S, Fabri BM. Left internal mammary artery usage in coronary artery bypass grafting: a measure of quality control. Ann Royal Coll Surg Engl. 2006;88(4):367-369. doi: 10.1308/003588406X98667.

6. Karthik S, Srinivasan AK, Grayson AD, Jackson M, Mediratta NK. Left internal mammary artery to the left anterior descending artery: effect on morbidity and mortality and reasons for nonusage. Ann Thorac Surg. 2004;78(1):142-148. doi: 10.1016/j.athoracsur.2004.02.025

7. Cohn LH. Use of the internal mammary artery graft and inhospital mortality and other adverse outcomes associated with coronary artery bypass surgery. Circulation. 2001;103(4):483-484.

8. Sher-i-Murtaza M, Baig MA, Raheel HM. Early outcome of Coronary Artery Bypass Graft Surgery in patients with significant Left Main Stem stenosis at a tertiary cardiac care center. Pak J Med Sci. 2015;31(4):909-914. doi: 10.12669/ pjms.314.7597

9. Martin GB, Rivers EP, Paradis NA, Goetting MG, Morris DC, Nowak RM. Emergency department cardiopulmonary bypass in the treatment of human cardiac arrest. Chest. 1998;113(3):743-751. doi: 10.1378/chest.113.3.743

10. Safar P, Abramson NS, Angelos M, Cantadore R, Leonov Y, Levine R, et al. Emergency cardiopulmonary bypass for resuscitation from prolonged cardiac arrest. Am J Emerg Med. 1990;8(1):55-67. doi:10.1016/0735-6757(90)90298-E

11. Allen BS, Rosenkranz ER, Buckberg GD, Vinten-Johansen J, Okamoto F, Leaf J. High oxygen requirements of dyskinetic cardiac muscle. J Thorac Cardiovasc Surg. 1986;92(3 Pt 2):543-552.

12. Braunwald E. Myocardial oxygen consumption: the quest for its determinants and some clinical fallout. J Am Coll Cardiol. 1999;34(5):1365-1368. doi: 10.1016/S07351097(99)00428-3

\section{Authors' Contribution:}

MSM conceived, designed, did data collection and manuscript writing.

MARB did statistical analysis \& editing of manuscript.

MSM \& MARB did review and final approval of manuscript.
Authors:

1. Dr. Muhammad Sher-i-Murtaza, (MBBS, FCPS). Assistant Professor of Cardiac Surgery, Ch. Pervaiz Elahi Institute of Cardiology (CPEIC), Multan, Pakistan.

2. Mr. Mirza Ahmad Raza Baig, (B. Sc. (Hons.) Cardiac Perfusion Technology), Clinical Perfusionist (Specialist), Cardiac Center at Hail Region, Hail, Saudi Arabia. 